\title{
Gunshot Wound: Reconstruction of an ankle defect in a five-year-old
}

\author{
by Volkan Tanaydin, MD, PharmD ${ }^{1 凶}$, Henri A.H. Winters, MD, PhD ${ }^{1}$,Wim R. Hogeboom, MD, PhD ${ }^{2}$ \\ , Elgun A.V.C.M. Zeegers, MD, PhD ${ }^{3}$, Oliver T. Zöphel, $\mathrm{MD}, \mathrm{PhD}^{4}$
}

The Foot and Ankle Online Journal 4 (8): 2

Reconstruction of a severe traumatic bone and soft tissue defect of the ankle region is a great challenge for the reconstructive surgeon. We report a case where we used a pedicled vascularized fibular transfer in combination with the transposition of a local fasciocutaneous flap to reconstruct a gunshot injury in a child. We achieved a successful repair without the use of free flaps. We believe that this approach provided a safe and relatively simple solution with minimal donor site morbidity.

Key words: Gunshot wound, Gustilo classification, limb salvage, pedicled vascularized fibular transfer.

Accepted: July, $2011 \quad$ Published: August, 2011

This is an Open Access article distributed under the terms of the Creative Commons Attribution License. It permits unrestricted use, distribution, and reproduction in any medium, provided the original work is properly cited. @The Foot and Ankle Online Journal (www.faoj.org), 2011 All rights reserved.

$\mathrm{R}$ econstruction of a severe traumatic bone and soft tissue defect of the ankle region in a growing child is a great challenge for the reconstructive surgeon. In traumatic limb injuries, limb salvage and tissue replacement are important to obtain a functional result. In children especially, the consideration for future growth needs to be addressed. Historically, various reconstructive techniques have been described for the treatment of bony defects.

Address correspondence to: Henri A.H. Winters, $\mathrm{MD}, \mathrm{PhD}$

VU Medical Center, 4D128, P.O. Box 7057, 1007MB Amsterdam

Email: $\underline{\text { h.winters@vumc.nl }}$

${ }^{1}$ VU Medical Center, Department of Plastic, Reconstructive and Hand Surgery, Amsterdam.

${ }^{2}$ Medisch Spectrum Twente, Department of Traumatology, Enschede.

${ }^{3}$ Medisch Spectrum Twente, Department of Orthopedics, Enschede.

${ }^{4}$ Medisch Spectrum Twente, Department of Plastic, Reconstructive and Hand Surgery, Enschede.
The use of non-vascularized cancellous bone grafts ${ }^{1,2}$ and Ilizarov bone lengthening ${ }^{3,4}$ have been advocated for defects measuring up to $5 \mathrm{~cm}$. Larger defects usually require a more complex reconstruction. More specifically, in the case of a large tibial defect, reconstructions using various vascularized bone autografts have been described in the literature. Since the introduction by Taylor, et $\mathrm{al}^{5}$., the free vascularized fibular graft $^{6-8}$ has become a standard practice. 


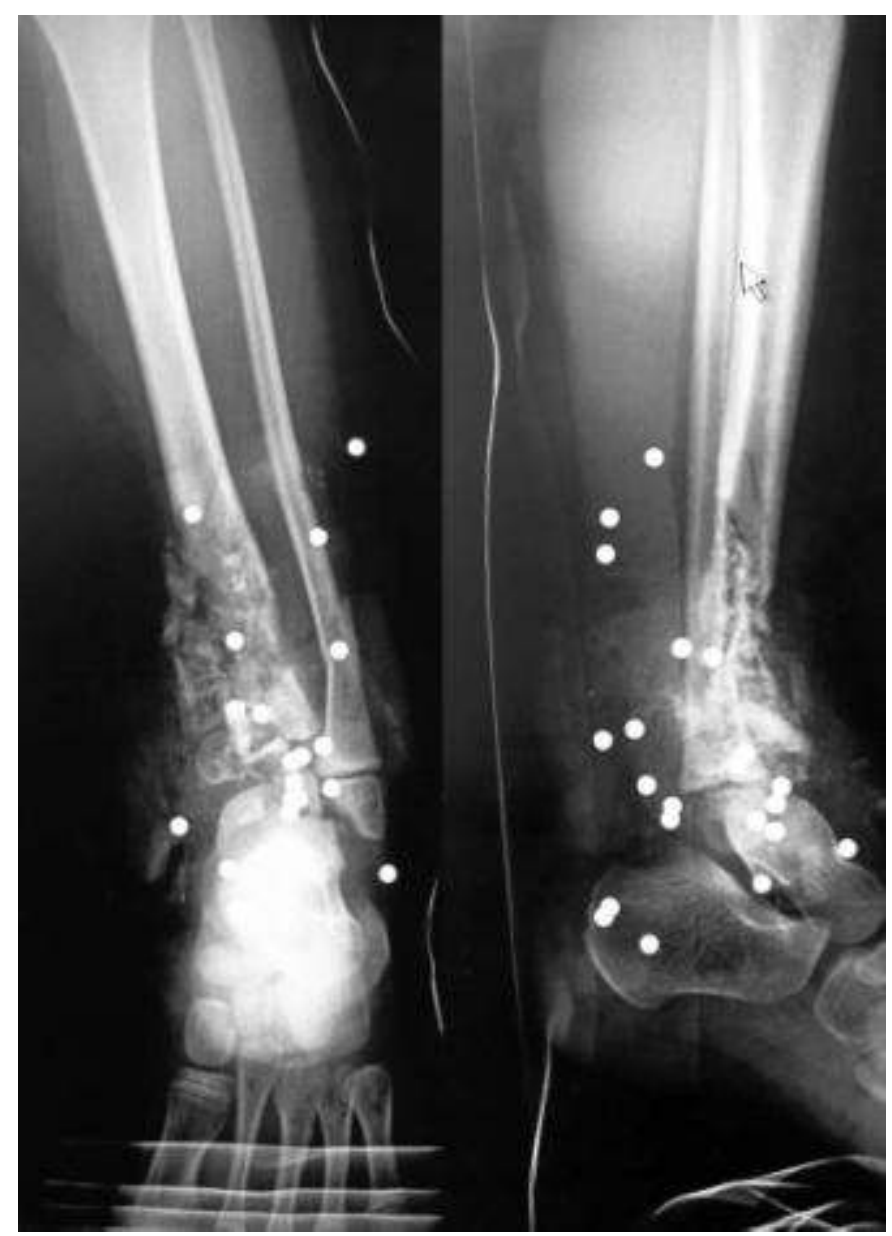

Figure 1 Radiograph of the left lower extremity. There is a large defect of the tibia and a fracture of the distal fibula. Note the many pellets in the ankle region.

However, the required microsurgical anastomosis and the risk of donor site morbidity make this procedure unpredictable and not always feasible. In these cases, the pedicled vascularized fibula transfer ${ }^{8-11}$ could be an alternative approach. We report a unique case in which a pedicled vascularized fibular transfer in combination with the transposition of a local fasciocutaneous flap was used to reconstruct a severe Gustilo IIIC grade gunshot injury in a growing child. The parents of our patient gave informed consent for publication of the report and any accompanying images.

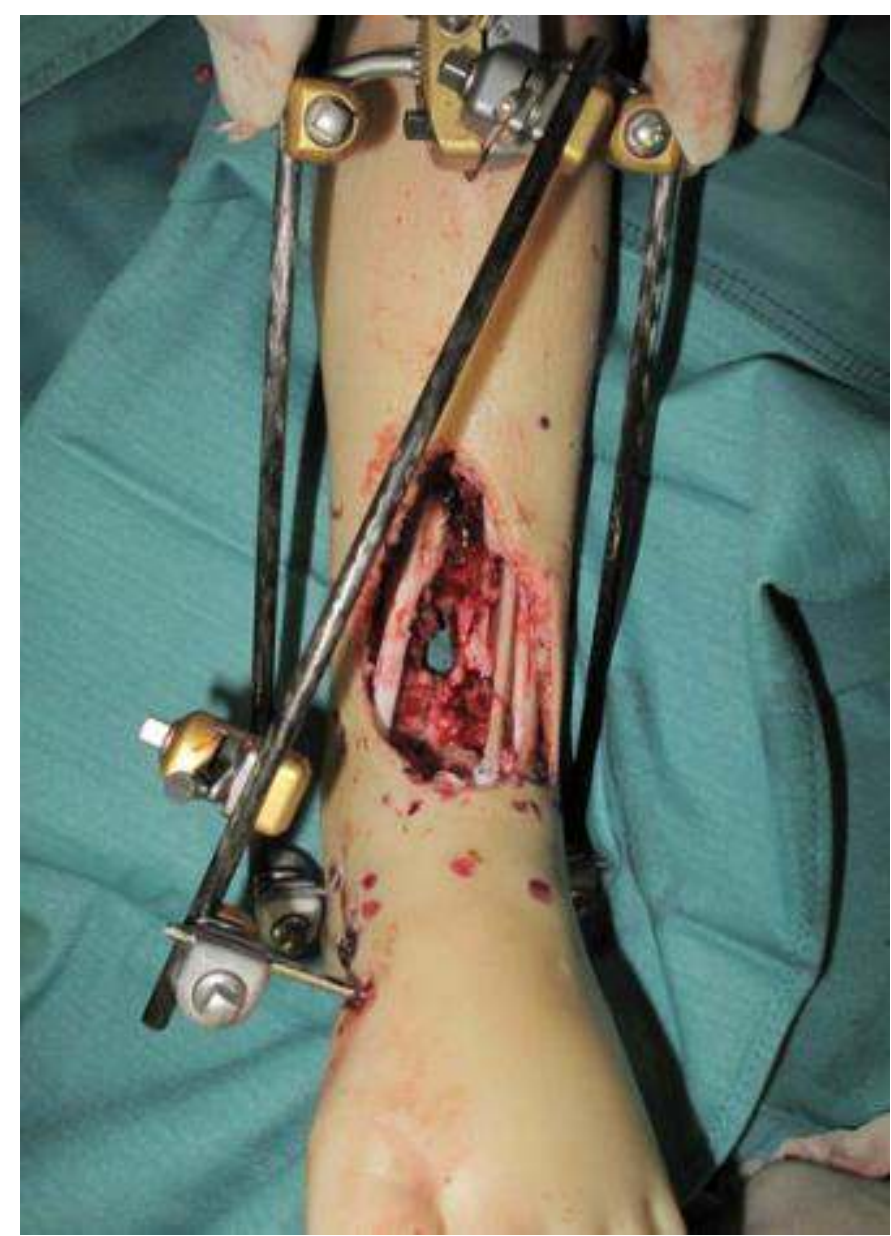

Figure 2 The defect of the tibia is measuring approximately 10 centimeter after debridement and placement of the Hoffman external fixator.

\section{Case report}

A five year-old girl sustained an accidental shotgun injury to her left lower extremity. The shotgun shell, loaded with $3 \mathrm{~mm}$ diameter steel pellets, was fired from a very short distance, causing extensive bone and soft-tissue loss of the ankle region. (Fig. 1) On examination, there was complete destruction of the talocrural joint, the anterior tibial artery and the tendon of the anterior tibial muscle. The extensor hallucis longus, extensor digitorum longus and flexor hallucis longus muscles, as well as the posterior tibial artery seemed to be intact and the circulation of the foot was adequate. There was diminished sensation in the sole of the foot, but it was not possible to tell whether this was due to neuropraxia or more serious damage of the tibial nerve. 


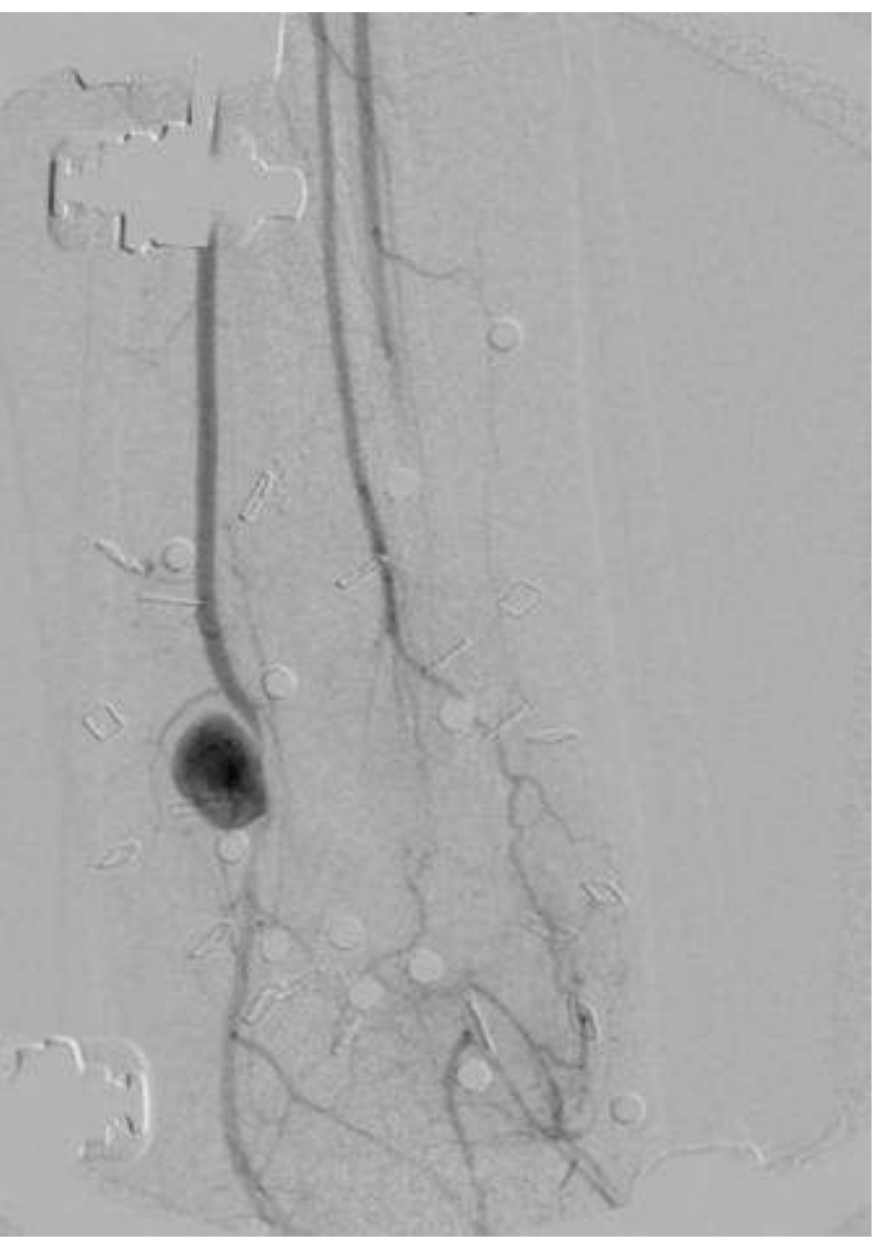

Figure 3 Angiography of the affected leg. There is retrograde filling of the dorsalis pedis by the posterior tibial artery. The distal third of the anterior tibial artery is not filled. Note the pseudoaneurysm in the posterior tibial artery.

Debridement of bone and soft tissue was performed under general anesthesia followed by fixation with a Hoffman external fixator, leaving a $10 \mathrm{~cm}$ defect of the distal tibia and soft-tissue loss, measuring $6 \times 8 \mathrm{~cm}$ ventrally and 5x6cm posterolaterally. (Fig.2)

During a second and third-look operation, the wound was again debrided and gentamicin beads were implanted within the wound. Most of the pellets from the gun shot were removed successfully during these procedures. An angiography was also performed during the third debridement. (Fig.3) This showed a retrograde blood flow from the posterior tibial artery to the dorsalis pedis artery with an interruption in the anterior tibial artery.

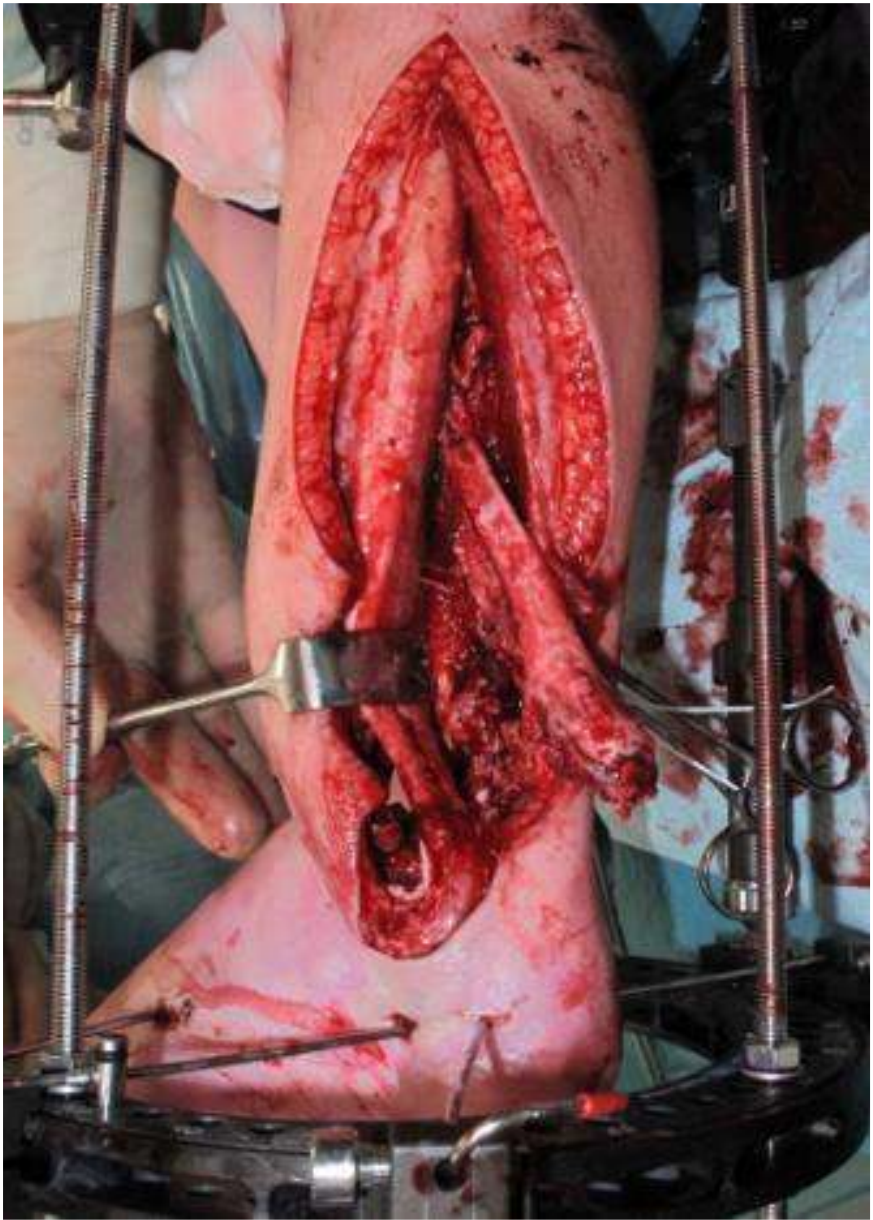

Figure 4 Ipsilateral Vascularized Fibular Transfer performed. Note the incision made as an extension of the existing posterolateral wound.

The communicating branch between the peroneal and posterior tibial artery was not seen. It also revealed a pseudoaneurysm in the posterior tibial artery, just above the medial malleolus.

As the child's parents requested no operations but to the affected leg - thereby precluding the use of free flaps - we opted for a pedicled ipsilateral vascularized fibula transfer, combined with a local soft tissue transfer and a split-thickness skin graft.

The patient was transferred to the VUMC hospital, where an ipsilateral vascularized fibula transfer was performed to reconstruct the distal tibia. The fibula, including the distal portion with the growth plate, was harvested through the posterolateral wound and transposed on its vascular pedicle to the tibial defect. 


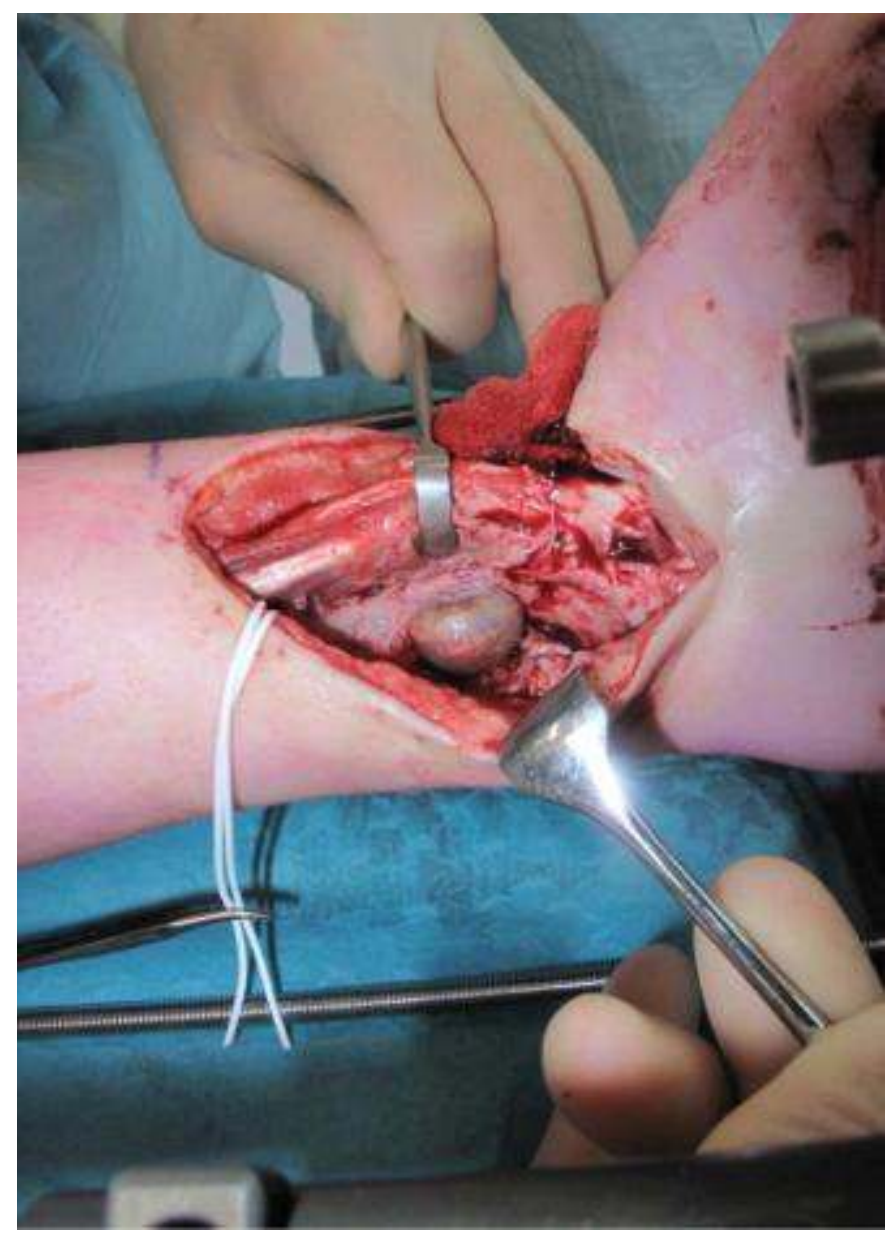

Figure $\mathbf{5}$ The pseudoaneurysm is resected and replaced by a vein graft of the right greater saphenous vein.

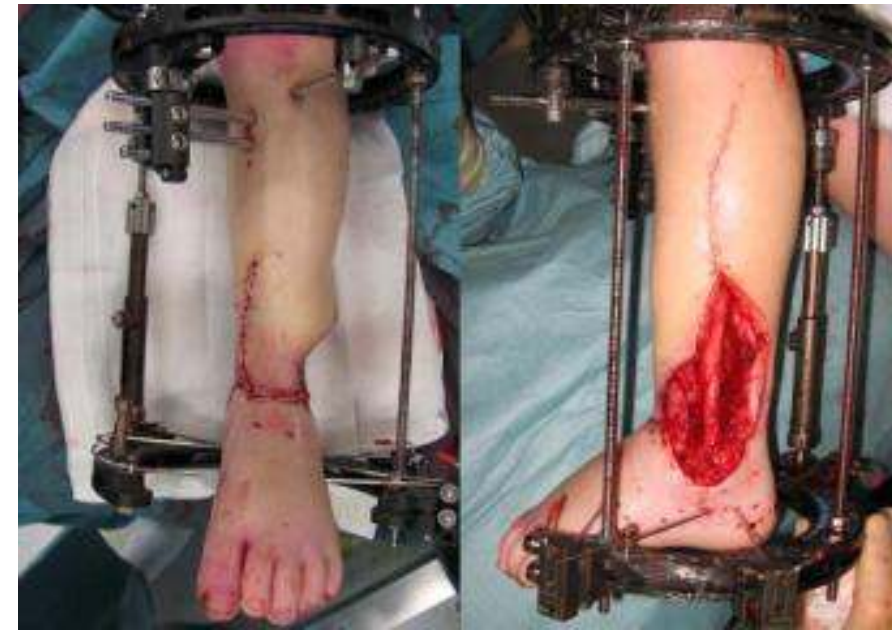

Figure 6 Local transposition of the fasciocutaneous flap to close the anteromedial defect.

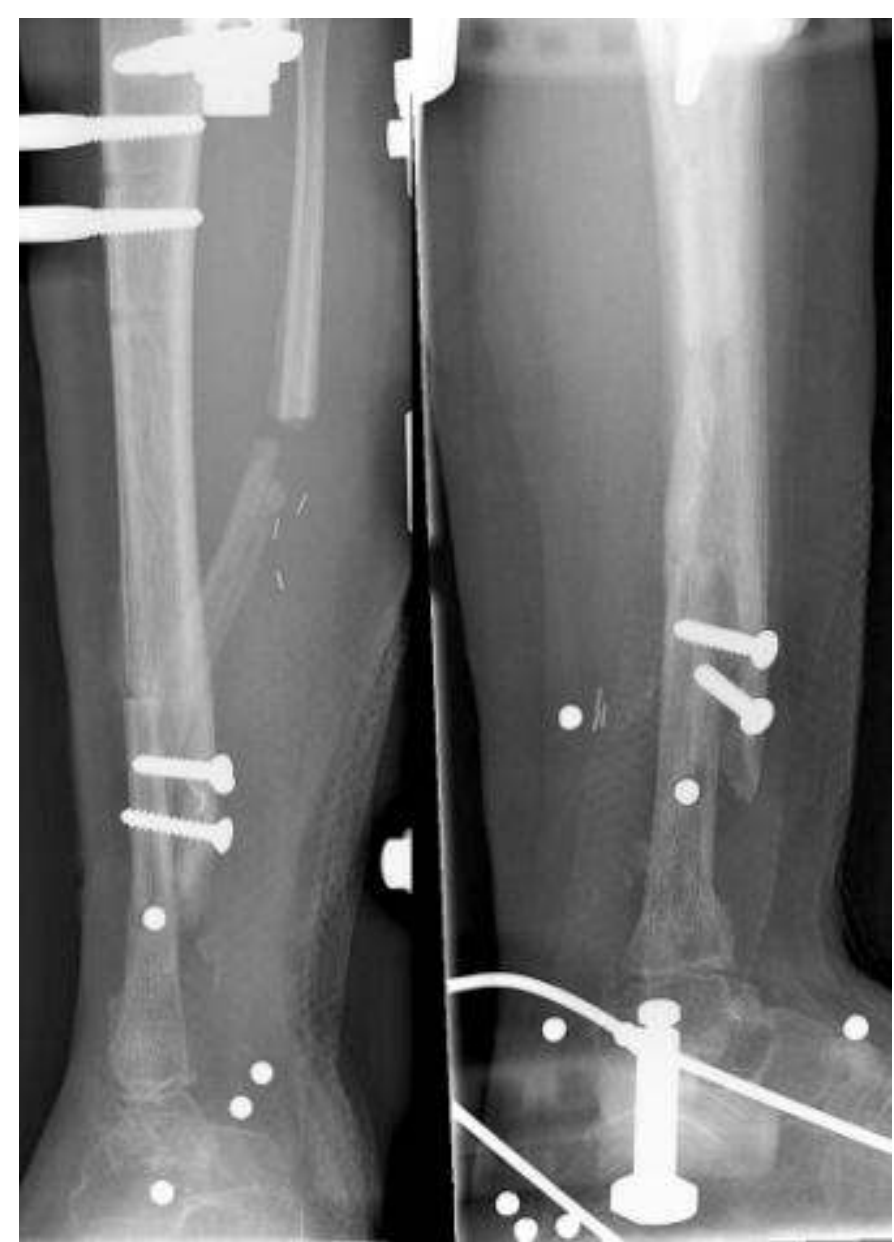

Figure 7 Postoperative radiograph show the fibula, including the growth plate. The fibula is transferred to the tibial defect and is wedged into the talar bone.

The distal portion was wedged into the remains of the talar bone and the proximal end was inserted into a slot in the tibial shaft. (Fig. 4) An external ring fixator (Orthofix) was placed. The pseudoaneurysm in the posterior tibial artery was resected and replaced with a vein graft from the right greater saphenous vein. (Fig. 5)

The tibial nerve was inspected and appeared to be completely intact. The anterior defect was closed with a transposition of a fasciocutaneous flap from the anterolateral side of the leg, leaving a posterolateral defect only instead of an anterior and posterior defect. (Figs. 6 and 7) 


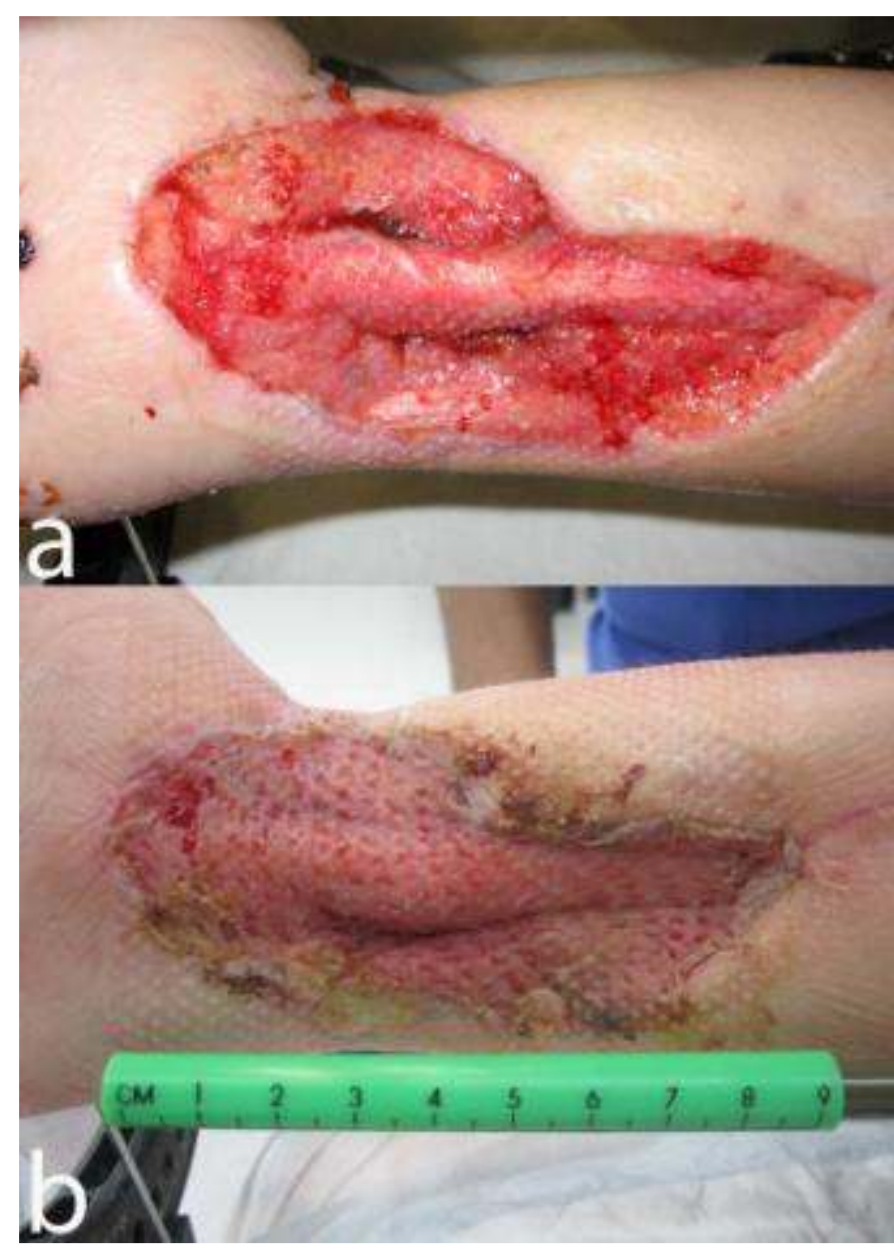

Figure 8 Wound healing after Negative Pressure Wound Therapy (a) and after Split-skin grafting. (b)

This remaining defect was treated with Negative Pressure Wound Therapy (NPW'T) and after three weeks this defect was covered by a split-thickness skin graft and again treated with NPWT. (Figs. 8A and $8 \mathrm{~B}$ ). Complete clinical wound healing was obtained a few weeks later. Six months after surgery the patient developed a pin-tract infection. This was successfully treated by four weeks of intravenous antibiotics and replacement of the external ring fixator by a walking cast.

One year after surgery the radiographs show good consolidation and hypertrophy of the fibula graft. (Figs. 9 and 10) The walking cast will be replaced by a removable patellabearing walking boot.

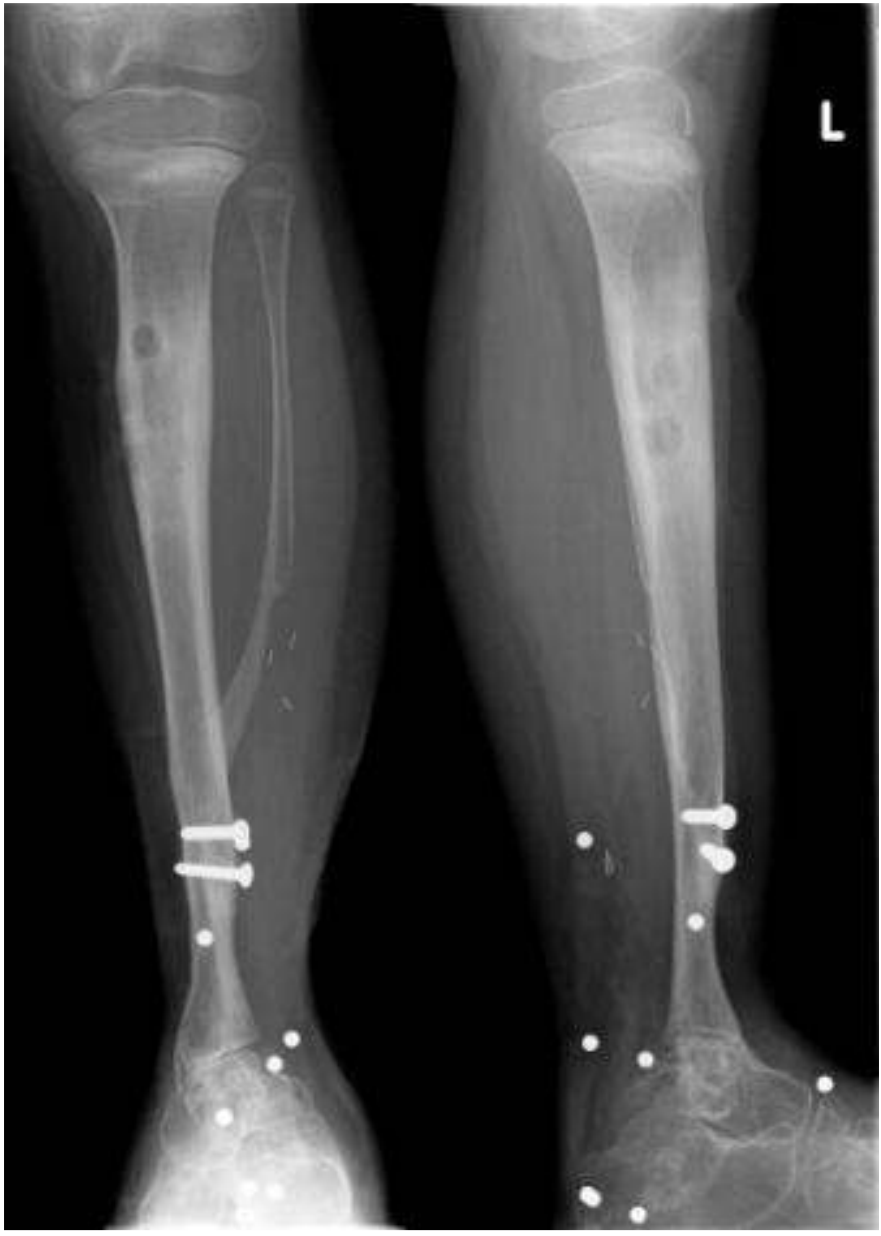

Figure 9 Radiograph of leg one year after reconstruction. Good bone consolidation and hypertrophy of the fibular graft is seen. Note also the pin-tracts in the proximal tibia.

The patient is up to full weightbearing and still receiving physical therapy. Her footsole sensation is recovering slowly, but gradually. She functions well with minimal disability and can perform normal activities of daily life such as walking, swimming and playing, without any pain or discomfort.

\section{Discussion}

Presently, reconstruction of large tibial defects using free $^{6-8}$ or pedicled ${ }^{8-11}$ vascularized fibular grafts is common. A disadvantage of using the fibula as a graft for tibial defects is that the fibula does not have the same strength as the tibia. 


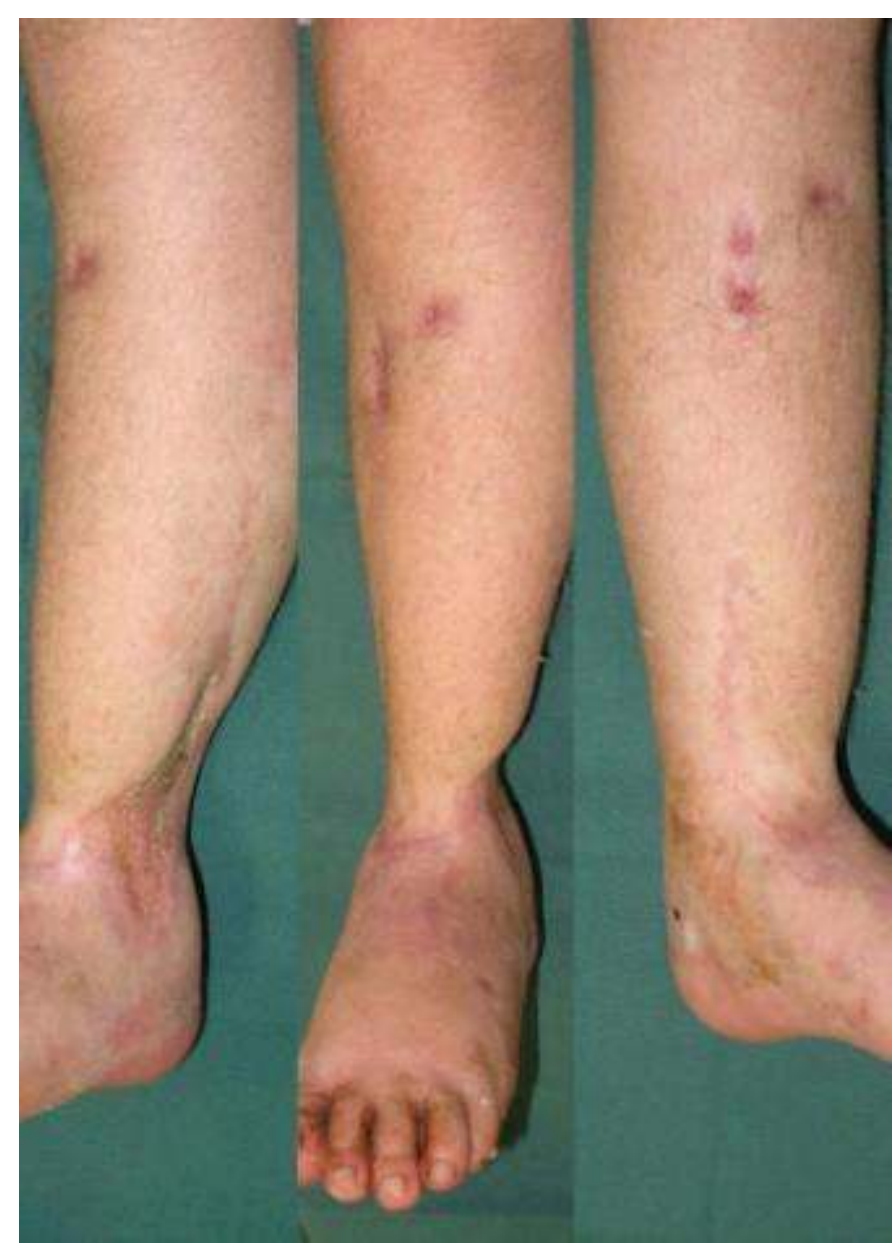

Figure 10 Three clinical views of the leg one year after reconstruction.

In time, however, the fibula hypertrophies under load and has the potential to achieve the weightbearing capacity of the tibia. Weiland, et al., ${ }^{12}$ describe an average time of 15 months to full weightbearing.

The decision to use either an ipsilateral pedicled fibula graft or a contralateral free vascularized fibula graft must be carefully considered for each individual case. A free vascularized fibula graft has the advantage of creating a great freedom of placement with no additional trauma caused to the injured leg. On the other hand, a free vascularized fibula graft calls for microsurgical anastomosis, with the risk of flap failure and creation of a separate donor site. An ipsilateral pedicled fibula graft may not always be feasible, but when it is utilized there is no need for microanastomosis and no separate donor site morbidity.

\begin{tabular}{|l|l|}
\hline \multicolumn{1}{|c|}{ Advantages } & \multicolumn{1}{c|}{ Disadvantages } \\
\hline $\begin{array}{l}\text { No need for } \\
\text { microanastomosis }\end{array}$ & $\begin{array}{l}\text { Additional trauma to } \\
\text { the affected leg. }\end{array}$ \\
$\begin{array}{l}\text { No need for donorsite } \\
\text { outside the affected area. }\end{array}$ & $\begin{array}{l}\text { Length of the pedicle } \\
\text { may be insufficient for } \\
\text { transfer. }\end{array}$ \\
$\begin{array}{l}\text { Very low risk of flap } \\
\text { failure. }\end{array}$ & $\begin{array}{l}\text { Loss of supplementary } \\
\text { mechanical support. }\end{array}$ \\
$\begin{array}{l}\text { Less operation time } \\
\text { compared to free flap. }\end{array}$ & \\
\hline
\end{tabular}

Table 1 Advantages and disadvantages of the pedicled vascularized fibular transfer.

The donor site morbidity of a contralateral free fibula graft may be small ${ }^{13,14}$, but in a child, progressive valgus deformity of the donor ankle has been described. ${ }^{15,16}$ In this particular case, there was a destruction of the talocrural joint. Therefore the affected distal fibula was not needed for ankle stability in the future, enabling use of the ipsilateral distal fibula -including the growth plate- for reconstruction of the tibia.

The advantages and the disadvantages of both techniques are shown in Table 1. In our case, the decision was simplified by the fact that the child's parents wanted no operations outside of the affected leg. Depending on the angiographic findings in the lower leg, we used the antegrade-flow pedicled flap based on the peroneal vessels. The arterial circulation of the foot of our patient was and is only supplied by the posterior tibial artery. However, we do not expect long-term complications in this field. Oxford, et al. ${ }^{17}$ reported no complications in using a fibula-free flap in extremities with 100\% obstructive vascular disease in the anterior or posterior tibial artery.

The wound was treated with Negative Pressure Wound Therapy to promote granulation and wound contracture and to decrease the bacterial count. This approach is also described by Greer, et al. ${ }^{18}$ 
He suggests the role of subatmospheric dressing as an alternative to free flap for providing tissue coverage for certain small Gustilo grade IIIB or IIIC open tibial fractures. In the present case, we achieved a successful repair of a severe traumatic bone defect, without the use of free flaps. We believe that this approach provided a safe and relatively simple solution with minimal donor site morbidity.

\section{References}

1. Enneking WF, Eady JL, Burchardt H. Autogenous cortical bone grafts in the reconstruction of segmental skeletal defects. JBJS 1980 62A: 1039-1058.

2. Green SA. Skeletal defects. A comparison of bone grafting and bone transport for segmental skeletal defects. Clin Orthop Relat Res 1994 301: 111-117.

3. Paley D, Maar DC. Ilizarov bone transport treatment for tibial defects. J Orthop Trauma 2000 14: 76-85.

4. Cierny G 3rd, Zorn KE. Segmental tibial defects. Comparing conventional and Ilizarov methodologies. Clin Orthop Relat Res 1994 301: 118-123.

5. Taylor GI, Miller GD, Ham FJ. The free vascularized bone graft. A clinical extension of microvascular techniques. Plast Reconstr Surg 1975 55: 533-544.

6. Hsieh CH, Jeng SF, Chen SH, Wei FC. Folded free vascularized fibular grafts for the reconstruction of combined segmental bone defects of distal tibia and fibula. J Trauma 2004: 56: 437-439.

7. Sharma S, Tiwari P, Kasabian AK, Longaker MT.

Reconstruction of a tibial defect with microvascular transfer of a previously fractured fibula. Ann Plast Surg 2000 45: 202-206.

8. Chung DW, Han CS, Lee, JH. Reconstruction of

composite tibial defect with free flaps and ipsilateral vascularized fibular transposition. Microsurgery 2011 31: 340-346.

9. Atkins RM, Madhavan P, Sudhakarb J, Whitwell D. Ipsilateral vascularised fibular transport for massive defects of the tibia. 1999 JBJS 81B: 1035-1040.

10. Hertel R, Pisan M, Jakob RP. Use of the ipsilateral vascularised fibula for tibial reconstruction. JBJS 1995 77B: 914-919.

11. Goren D, Sapir O, Stern A, Nyska M. Ipsilateral fibular transfer for a large tibial defect caused by a gunshot injury: case report. Mil Med 2005 170, 418-421.

12. Weiland AJ, Moore JR, Daniel RK. Vascularized bone autografts. Experience with 41 cases. Clin Orthop Relat Res 1983 174: 87-95.

13. Lee EH, Goh JC, Helm R, Pho RW. Donor site morbidity following resection of the fibula. JBJS 1990 72B: 129-131.

14. Goodacre TE, Walker CJ, Jawad AS, Jackson AM, Brough MD. Donor site morbidity following osteocutaneous free fibula transfer. Br J Plast Surg 1990 43: 410-412.

15. Wiltse LL. Valgus deformity of the ankle: a sequel to acquired or congenital abnormalities of the fibula. JBJS 1942 54A: 595-606.

16. Hsu LC, Yau AC, O'Brien JP, Hodgson AR. Valgus deformity of the ankle resulting from fibular resection for a graft in subtalar fusion in children. JBJS 1972 54A: 585-594.

17. Oxford L, Ducic Y. Use of fibula-free tissue transfer with preoperative 2-vessel runoff to the lower extremity. Arch Facial Plast Surg 2005 7: 261-264; discussion 265.

18. Greer S, Greer S, Kasabian A, Thorne C, Borud L, Sims $\mathrm{CD}, \mathrm{Hsu} \mathrm{M}$. The use of a subatmospheric pressure dressing to salvage a Gustilo grade IIIB open tibial fracture with concomitant osteomyelitis to avert a free flap. Ann Plast Surg 1998 41: 687. 